\title{
ANALISA KUALITAS AUTOMOTIVE DIESEL OIL (ADO) SESUAI DENGAN BAKU MUTU YANG BEREDAR DI MASYARAKAT
}

\section{AUTOMOTIVE DIESEL OIL (ADO) QUALITY ANALYSIS IN ACCORDANCE WITH THE QUALITY STANDARS CIRCULATING IN THE COMMUNITY}

\author{
Indah Agus Setiorini ${ }^{1}$ \\ 1Teknik Pengolahan Migas Politeknik Akamigas Palembang, 30257, Indonesia \\ Corresponding Author E-mail: indahagussetiorini_sukarman@yahoo.co.id
}

\begin{abstract}
Automotive Diesel Oil (ADO) is a clear brownish yellow distillate type fuel, slightly thicker than kerosine, with boiling routes ranging from $180{ }^{\circ} \mathrm{C}$ to $370{ }^{\circ} \mathrm{C}$, used as fuel for high speed diesel engines (larger from $1.000 \mathrm{rpm}$ ), such as: public vehicles, trucks, trailers, eartheners, tractors, trains, etc. Automotive Diesel Oil (ADO) is also called gasoil or HSD (High Speed Diesel Oil). The aim of evaluating the quality of Automotive Diesel Oil (ADO) is to know whether Automotive Diesel Oil (ADO) circulating in the community meets marketing requirements, especially automotive or diesel engines. Some test parameters that are carried out are in the form of : Specific gravity, Burning Properties (ignation quality), and volatility. The results of the ADO fuel test from various gas stations provide an illustration that the nature or characteristics of the ADO oil studied are generally still meeting the specifications both used as diesel engine fuel and transaction and transportation requirements. From the results of the Specific Gravity analysis, the range is $0,820-0,870$, ie 0,850 to 0,852 . For the Analysis of Combustion Properties with the Calculated Cetane Index (CCI) ASTM D-976 Method where the average cetane index ranges from $47-48$ which is above the specifications (min 45). Analysis of Evaporation Properties with the ASTM D-86 distillation method shows that the FBP temperature meets the specifications which is $<370^{\circ} \mathrm{C}$.

Keywords: Automotif Diesel Oil (ADO), Spesific Gravity, Iqnation quality, Volatility
\end{abstract}

Abstrak: Automotif Diesel Oil (ADO) adalah bahan bakar jenis distilat berwarna kuning kecoklatan yang jernih, sedikit lebih kental dari pada minyak tanah atau kerosine, dengan trayek didih berkisar antara $180{ }^{\circ} \mathrm{C}$ sampai $370{ }^{\circ} \mathrm{C}$, digunakan sebagai bahan bakar untuk mesin diesel berkecepatan tinggi (lebih besar dari 1000 rpm), seperti : kendaraan umum, truk, trailer, alat-alat penggusur tanah, traktor, kereta api, dll. Automotif Diesel Oil (ADO) disebut juga gasoil atau HSD (High Speed Diesel Oil). Tujuan dari evaluasi kualitas Automotif Diesel Oil (ADO) ini yaitu untuk tahu apakah Automotif Diesel Oil (ADO) yang beredar di masyarakat memenuhi syarat pemasaran terutama peruntukan automotif atau mesin diesel. Beberapa parameter uji yang dilakukan, yaitu berupa : Berat Jenis (spesific gravity), Sifat Pembakaran (ignation quality), dan Sifat Penguapan (volatility). Hasil pegujian bahan bakar ADO dari berbagai SPBU memberikan gambaran bahwa sifat atau karakteristik minyak ADO yang diteliti umumnya masih memenuhi spesifikasi baik digunakan sebagai bahan bakar mesin diesel maupun persyaratan transaksi dan transportasi. Dari hasil analisa Spesific Gravity berada di range 0,820 - 0,870, yaitu 0,850 sampai dengan 0,852. Untuk Analisa Sifat Pembakaran dengan Metode Calculated Cetane Index (CCI) ASTM D-976 dimana rata-rata cetane index berkisar 47 - 48 yaitu diatas spesifikasi (min 45). Analisa Sifat Penguapan dengan metode distilasi ASTM D-86 menunjukkan bahwa temperatur FBP memenuhi spesifikasi yaitu $<370^{\circ} \mathrm{C}$.

Kata Kunci : Automotif Diesel Oil (ADO), Spesific Gravity, Sifat Pembakaran, Sifat Penguapan

\section{PENDAHULUAN}

Diesel yang berasal dari minyak nabati merupakan bahan bakar yang disebut biodiesel yang dapat diperbaharui (renewable), mudah diproses, harganya relatif stabil, tidak menghasilkan cemaran yang berbahaya bagi lingkungan (non toksik) serta mudah terurai secara alami. Untuk mengatasi kelemahan minyak sawit, maka minyak sawit itu harus dikonversi terlebih dahulu menjadi bentuk metil atau etil esternya.

Biodiesel merupakan kandidat yang paling baik untuk menggantikan bahan bakar fosil sebagai sumber energi transportasi utama dunia, karena Biodiesel merupakan bahan bakar terbaharui yang dapat menggantikan diesel petrol di mesin sekarang ini dan dapat diangkut dan dijual dengan menggunakan 
infrastruktur zaman sekarang. (Haryanto, 2002).

Meningkatnya kebutuhan bahan bakar berupa Automotive Diesel Oil tidak dapat dibendung, hal ini terbukti dengan munculnya Diesel Oil yang berasal dari nabati. Terdapat beberapa masyarakat yang memanfaatkan kondisi ini dengan membangun kilang tradisional. Kilang ilegal ini sangat menguntungkan bagi mereka. Ditinjau dari teknik pengolahan minyak bumi tentunya penyulingan yang mereka lakukan akan menghasilkan produksi fraksi-fraksi dengan kualitas yang tidak dapat dipertanggung jawabkan atau tidak sesuai dengan spesifikasi penjualan. Sehingga produk (Automotive Diesel Oil) yang mereka hasilkan dengan kualitas tidak sesuai baku mutu tersebut akan dilakukan pencampuran atau blending oleh pihak yang tidak bertanggung jawab. Berdasarkan hal tersebut maka peneliti melakukan penelitian secara bertahap, dimana saat ini peneliti hanya mampu mengevaluasi mutu Automotive Diesel Oil yang beredar di tiga SPBU X Kota Palembang.

Berikut beberapa analisa yang akan dilaksanakan meliputi :
1. Uji
Calculated
Cetane Index menggunakan Metode Uji ASTM D-976,

2. Uji Berat Jenis menggunakan Metode Uji ASTM D-4052/1298, dan

3. Uji Distilasi menggunakan Metode Uji ASTM D-86.

\section{TEORI DASAR}

Pada pembuatan Biodiesel dapat digunakan katalis basa $(\mathrm{KOH}, \mathrm{NaOH})$, asam $\left(\mathrm{H}_{2} \mathrm{SO}_{4}, \mathrm{HCl}\right)$ dan katalis padat sebagai pereaksi, biasanya paling banyak digunakan alkohol dari golongan methanol karena lebih efektif dan dapat memaksimalkan reaksi transesterifikasi pada minyak sebagai pereaksi, biasanya paling banyak digunakan alkohol dari golongan methanol karena lebih efektif dan dapat memaksimalkan reaksi transesterifikasi pada minyak. (Hikmah, 2010)

\subsection{Bahan Bakar Alternatif}

Produksi dan penggunaan BBM alternatif harus segera direalisasikan untuk menutupi kekurangan terhadap kebutuhan BBM fosil yang semakin meningkat. Biodiesel dapat dihasilkan dari bermacam sumber, seperti minyak nabati, lemak hewani dan sisa dari minyak atau lemak (misalnya sisa minyak penggorengan) (Hanif, 2009).

Biodiesel memiliki beberapa kelebihan dibanding bahan bakar diesel petroleum / fosil (ADO). Kelebihan tersebut antara lain sebagai berikut:

1. Merupakan bahan bakar yang tidak beracun dan dapat dibiodegradasi

2. Mempunyai bilangan cetana relatif tinggi.

3. Mengurangi emisi karbon monoksida, hidrokarbon dan NOx.

4. Terdapat dalam fase cair.

Bahan bakar diesel dikehendaki relatif mudah terbakar sendiri (tanpa harus dipicu dengan letikan api busi) jika disemprotkan ke dalam udara panas bertekanan. Tolok ukur dari sifat ini adalah bilangan cetana, yang didefinisikan sebagai \% volume n-cetana di dalam bahan bakar yang berupa campuran $\mathrm{n}$ cetana $\left(\mathrm{n}-\mathrm{C}_{16} \mathrm{H}_{34}\right)$ dan $\alpha$-metil naftalena $(\alpha$ $\left.\mathrm{CH}_{3}-\mathrm{C}_{10} \mathrm{H}_{7}\right)$ serta berkualitas pembakaran di dalam mesin diesel standar. n-cetana (suatu hidrokarbon berantai lurus) sangat mudah terbakar sendiri dan diberi nilai bilangan cetana 100, sedangkan $\alpha$-metil naftalena (suatu hidrokarbon aromatik bercincin ganda) sangat sukar terbakar dan diberi nilai bilangan cetana nol.

\subsection{Fungsi Automotive Diesel Oil (ADO)} Fungsi dari Automotive Diesel Oil (ADO) antara lain:

1. Sebagai bahan bakar mesin-mesin diesel.

2. Sebagai BBM kendaraan bermotor.

3. Melumasi mesin karena kekentalan lebih tinggi.

4. Bisa melarutkan kerak-kerak yang ada di mesin.

\subsection{Karakteristik Automotive Diesel Oil (ADO)}

Berikut beberapa karakteristik atau sifat-sifat penting Automotive Diesel Oil yang akan ditinjau pada penelitian ini :

a. Berat Jenis (spesific gravity) 


\section{b. Sifat Pembakaran (ignation quality) \\ c. Sifat Penguapan (volatility)}

Berikut adalah spesifikasi BBM jenis diesel 48 standar Pertamina :

Tabel 2.1 Spesifikasi BBM Jenis Diesel 48 Standar Pertamina

\begin{tabular}{|c|c|c|c|c|}
\hline \multirow{2}{*}{ No. } & \multirow{2}{*}{ Karaktoriatik } & \multirow{2}{*}{ Dentuan } & \multicolumn{2}{|c|}{ Eetoman } \\
\hline & & & Min & $\operatorname{Max}$ \\
\hline \multirow[t]{3}{*}{1} & Bilangan Cotana & 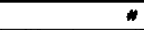 & & $\cdot$ \\
\hline & - Angken Cotang & & 48 & \\
\hline & - Indok Cotanna & & 46 & \\
\hline 2 & Barat Jeniage is is & $\mathrm{kg} / \mathrm{ms}$ & 81s & 870 \\
\hline 3 & Viakonitue $640^{\circ} \mathrm{C}$ & mmessese & 2,0 & 8.0 \\
\hline 4 & Kandungan Sultur & $96 \mathrm{~m} / \mathrm{m}$ & 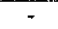 & 0.35 \\
\hline \multirow[t]{2}{*}{5} & Ditettaes: : & & & \\
\hline & $T 95$ & *c & - & 370 \\
\hline 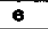 & Tritk Nyala & $\bar{c}$ & 60 & \\
\hline 7 & Thisk Tuang & ${ }^{\circ} \mathrm{c}$ & & 18 \\
\hline B & Peakdu Kerbon & $96 \mathrm{~m} / \mathrm{m}$ & & 0.1 \\
\hline 9 & Kandinganr Alr & $\mathrm{mg} / \mathrm{kg}$ & & 500 \\
\hline 10 & Biological Growth ") & & \multicolumn{2}{|c|}{ Nithit m } \\
\hline 11 & Kandungain FAME \#) & $\% \vee N$ & & 10 \\
\hline 12 & Kandungan Motanol \& Etanol ") & $96 \mathrm{v} / \mathrm{v}$ & \multicolumn{2}{|c|}{ Thdak terdeteksi } \\
\hline 13 & Korowt bilah tombngn & & \multicolumn{2}{|c|}{ Keies 1} \\
\hline 14 & Kandungan Abu & $\% \mathrm{~m} / \mathrm{m}$ & - & 0.01 \\
\hline 15 & Kandungan Sedimen & $\% \mathrm{~m} / \mathrm{m}$ & - & 0.01 \\
\hline 16 & Bilangan Aleam Kuat & mo кон " & . & 0.0 \\
\hline 17 & Bilangan Aoam Total & mg КОН $\Omega$ & - & 0,0 \\
\hline 18 & Partikulat & & - & - \\
\hline 19 & Ponampltan visual & & \multicolumn{2}{|c|}{ Jernin \& terang } \\
\hline 20 & Wame & No ASTM & - & 3.0 \\
\hline
\end{tabular}

Sumber : Pertamina, Maret 2016

\section{METODOLOGI PENELITIAN}

\subsection{Teknik Pengumpulan Data}

'Dalam mendapatkan data-data yang berhubungan dengan objek yang diteliti, Penulis menggunakan teknik pengumpulan data sebagai berikut :

1. Studi pustaka

Metode yang digunakan dengan cara mengumpulkan sumber-sumber berupa literatur yang dapat menunjang penelitian ini.

2. Metode observasi

Metode yang digunakan dengan cara pengamatan langsung atau terjun kelapangan untuk melihat langsung sampel yang digunakan untuk analisa produk.

3. Preparasi sampel

Metode yang digunakan dengan menerapkan sistem preparasi sampel di Laboratorium untuk analisa karekteristik automotive diesel oil.

\subsection{Teknik Analisis Data}

Analisis data yang digunakan pada penelitian ini antara lain:

1. Metode analisa berat jenis (spesific gravity): Density at $15^{\circ} \mathrm{C}$, metode ASTM D-1298 dan ${ }^{\circ}$ API.

2. Metode analisa sifat pembakaran (ignation quality): Calculated Cetane Index, metode ASTM D-976.

3. Metode analisa sifat penguapan (volatility): Distilasi, metode ASTM D86.

\section{HASIL DAN PEMBAHASAN}

\subsection{Hasil Analisa Produk Automotive Diesel Oil (ADO)}

Karakteristik atau sifat-sifat penting produk automotive diesel oil supaya dapat dipergunakan secara efektif sebagai bahan bakar mesin diesel diperlukan pengujian beberapa parameter terhadap produk automotive diesel oil. Sementara lingkup pembahasan sesuai pengelompokan parameter pengujian automotive diesel oil, yaitu :

a. Berat Jenis (spesific gravity),

b. Sifat Pembakaran (ignation quality), dan

c. Sifat Penguapan (volatility).

\subsection{Perhitungan Viscositas Kinematik}

Data Perhitungan Viscositas Kinematik

Aktual

Faktor Viscosimeter $\quad=0,0166$

Temperatur Pengujian $\quad=122{ }^{\circ} \mathrm{F} / 50{ }^{\circ} \mathrm{C}$

Waktu Pengujian, $\mathrm{t} \quad=$ second $/$ detik

Visc. Kinematic $122{ }^{\circ} \mathrm{F}=$ (Waktu $\mathrm{x}$

Factor Visc) cSt

Sampel 1

Factor Viscosimeter $\quad=0,0166$

Temperatur Pengujian $\quad=122{ }^{\circ} \mathrm{F} / 50{ }^{\circ} \mathrm{C}$

Waktu Pengujian, $\mathrm{t} \quad=240$ detik

Visc. Kinematic $122{ }^{\circ} \mathrm{F}=(240 \times 0,0166)$

$\mathrm{cSt}=3,98 \mathrm{cSt}$

Sampel 2

Factor Viscosimeter $\quad=0,0166$

Temperatur Pengujian $\quad=122{ }^{\circ} \mathrm{F} / 50{ }^{\circ} \mathrm{C}$

Waktu Pengujian, $\mathrm{t}=251$ detik 
Visc. Kinematic $122{ }^{\circ} \mathrm{F} \quad:(251 \times 0,0166)$

$\mathrm{cSt}=4,17 \mathrm{cSt}$

\section{Sampel 3}

Faktor Viscosimeter $\quad=0,0166$

Temperatur Pengujian $\quad=122{ }^{\circ} \mathrm{F} / 50{ }^{\circ} \mathrm{C}$

Waktu Pengujian, $\mathrm{t}=248$ detik

Visc. Kinematic $122^{\circ} \mathrm{F}=(248 \times 0,0166)$ $\mathrm{cSt}=4,12 \mathrm{cSt}$

Data Viscosity Kinematic (VC) Teoritis

(D.Q. Kern, Process Heat Transfer, hal. 820)

$$
\begin{gathered}
\mathrm{Cp}=\mathrm{cSt} \times \mathrm{SG} 60 / 60^{\circ} \mathrm{F} \\
\mathrm{cSt}=\frac{\mathrm{cp}}{\mathrm{SG} 60 / 60^{\circ} \mathrm{F}}
\end{gathered}
$$

(Fiq.13.a. Visc. Conversion Chart (D.Q. Kern) Konversi Centipoise ke Centistokes :

$$
{ }^{\circ} \mathrm{API}=\frac{141,5}{\mathrm{SG} 60 / 60^{\circ} \mathrm{F}}-131,5
$$

See page 820 , Lihat fiq. 14. Visc. of Liquid pada $\mathrm{T}=122^{\circ} \mathrm{F}$, dengan menghubungkan sumbu $\mathrm{x}$ dan $\mathrm{y}$, maka dari grafik didapat nilai Viscositas Kinematik dalam Centipoise.

Sampel 1

SG $60 / 60{ }^{\circ} \mathrm{F}=0,852$

$35^{\circ}$ API distilate $(\mathrm{x}=10,0 ; \mathrm{y}=20,0)=2,8 \mathrm{cp}$

$$
\mathrm{cSt}=\frac{\mathrm{cp}}{\mathrm{SG} 60 / 60^{\circ} \mathrm{F}}=\frac{2,8}{0,852}=3,29 \mathrm{cSt}
$$

\section{Sampel 2}

$\mathrm{SG} 60 / 60^{\circ} \mathrm{F}=0,850$

$34,9^{\circ}$ API distilate $(\mathrm{x}=10,0 ; \mathrm{y}=20,0)=2,8$ cp

$$
\mathrm{cSt}=\frac{\mathrm{cp}}{\mathrm{SG}}=\frac{2,8}{0,850}=3,30 \mathrm{cSt}
$$

\section{Sampel 3}

SG $60 / 60^{\circ} \mathrm{F}=0,813$

$42,5^{\circ}$ API distilate $(\mathrm{x}=11,5 ; \mathrm{y}=17,4)=1,5$ $\mathrm{cp}$

$$
\mathrm{cSt}=\frac{\mathrm{cp}}{\mathrm{SG}}=\frac{1,5}{0,813}=1,85 \mathrm{cSt}
$$

\subsection{Pembahasan}

\subsubsection{Berat Jenis (Spesific Gravity)}

Sifat penting minyak solar salah satunya adalah spesifik gravity $60 / 60^{\circ} \mathrm{F}$ dengan range 0,820-0,870. Hasil analisa sampel dari berbagai SPBU di laboratorium menunjukkan hasil yang memenuhi syarat pemasaran.
Dengan demikian, maka untuk perhitungan berat per satuan volume atau sebaliknya volume per satuan berat tidak bermasalah dalam hal transaksi jual beli atau dalam hal

\begin{tabular}{|c|c|c|c|c|c|c|c|}
\hline \multirow[b]{2}{*}{ No. } & \multirow[b]{2}{*}{ Parameter Uji } & \multirow[b]{2}{*}{$\frac{\frac{0}{0}}{\sum}$} & \multirow[b]{2}{*}{$\underset{\tilde{E}}{\stackrel{\Xi}{\Xi}}$} & \multirow{2}{*}{ 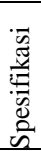 } & \multicolumn{3}{|c|}{ Hasil } \\
\hline & & & & & $\mathrm{S}_{1}$ & $\mathrm{~S}_{2}$ & $\mathrm{~S}_{3}$ \\
\hline 1 & $\begin{array}{c}\text { Spesifik } \\
\text { Gravity } 60 / 60 \\
{ }^{\circ} \mathrm{F}\end{array}$ & 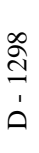 & - & $\begin{array}{l}0 \\
\infty \\
0 \\
0 \\
1 \\
0 \\
\infty \\
0 \\
0\end{array}$ & $\begin{array}{l}1 \\
\infty \\
0 \\
0\end{array}$ & $\begin{array}{l}\circ \\
\infty \\
0 \\
0\end{array}$ & $\frac{m}{\infty}$ \\
\hline 2 & $\begin{array}{c}\text { Calculated } \\
\text { Cetane Index }\end{array}$ & $\frac{0}{a}$ & - & $\begin{array}{l}\stackrel{n}{+} \\
\dot{\Xi}\end{array}$ & 47 & 47 & 48 \\
\hline 3 & Distilasi: & $\begin{array}{l}\infty \\
\infty \\
1 \\
0\end{array}$ & - & - & - & - & - \\
\hline 4 & IBP & - & ${ }^{\circ} \mathrm{C}$ & & 156 & 158 & 152 \\
\hline 5 & $10 \%$ Vol rec & - & ${ }^{\circ} \mathrm{C}$ & & 194 & 193 & 194 \\
\hline 6 & $20 \% \mathrm{Vol} \mathrm{rec}$ & - & ${ }^{\circ} \mathrm{C}$ & & 220 & 222 & 220 \\
\hline 7 & $30 \%$ Vol rec & - & ${ }^{\circ} \mathrm{C}$ & & 247 & 246 & 244 \\
\hline 8 & $40 \%$ Vol rec & - & ${ }^{\circ} \mathrm{C}$ & & 269 & 266 & 263 \\
\hline 9 & $50 \% \mathrm{Vol} \mathrm{rec}$ & - & ${ }^{\circ} \mathrm{C}$ & & 284 & 282 & 276 \\
\hline 10 & $60 \%$ Vol rec & - & ${ }^{\circ} \mathrm{C}$ & & 298 & 298 & 292 \\
\hline 11 & $70 \%$ Vol rec & - & ${ }^{\circ} \mathrm{C}$ & & 312 & 310 & 307 \\
\hline 12 & $80 \%$ Vol rec & - & ${ }^{\circ} \mathrm{C}$ & & 325 & 323 & 322 \\
\hline 13 & $90 \% \mathrm{Vol} \mathrm{rec}$ & - & ${ }^{\circ} \mathrm{C}$ & & 340 & 338 & 334 \\
\hline 14 & FBP & - & ${ }^{\circ} \mathrm{C}$ & 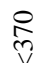 & 355 & 356 & 340 \\
\hline 15 & Residu & - & $\begin{array}{l}3 \\
0 \\
0\end{array}$ & & 2,5 & 2,0 & 2,5 \\
\hline 16 & Loss & - & $\begin{array}{l}0 \\
0 \\
0\end{array}$ & & 1,0 & 1,0 & 1,0 \\
\hline 17 & $\begin{array}{c}\text { Recovery at } \\
300{ }^{\circ} \mathrm{C}\end{array}$ & - & $\begin{array}{l}3 \\
j \\
0\end{array}$ & $\begin{array}{l}\stackrel{8}{+} \\
\stackrel{3}{\Sigma}\end{array}$ & 62 & 62 & 65 \\
\hline
\end{tabular}
transportasi. Demikian juga analisa warna berada di bawah max 3,0, yaitu: 2,0 sampai dengan 2,5.

\subsection{Tabel Data Hasil Pegujian Produk Diesel di SPBU X Palembang}

\subsubsection{Sifat Pembakaran}

Dalam mesin diesel, bahan bakar berupa solar dan udara ditekan sehingga suhu dan tekanan diruang bakar menjadi tinggi yang mengakibatkan solar mengalami penyalaan sendiri (self iqnation). Terjadinya self iqnation 
ini diidentifikasikan dengan parameter Cetane Number (ASTM D-613) atau dengan Calculated Cetane Index (ASTM D-976) yang dilaksanakan di laboratorium PT Pertamina RU III Plaju.

Hasil analisa calculated cetane index terhadap contoh solar dari SPBU diperoleh angka rata-rata calculated cetane index berkisar $47 \mathrm{~s} / \mathrm{d} 48$ yaitu diatas spesifikasi (min 45). Hal ini menggambarkan bahwa sifat pembakaran terjadi self iqnation di ruang bakar yang cukup baik.

\subsubsection{Sifat Penguapan}

Meskipun solar merupakan bahan bakar tidak mudah menguap, namun proses pembakaran harus tetap terjadi dengan bantuan sistem pengabutan/atomisasi fuel melalui injektor pump sehingga proses pembakaran tetap berlangsung. Mudahnya penguapan diidentifikasikan dengan analisa Distilasi yaitu dengan metode ASTM D-86. Hasil distilasi menunjukkan bahwa temperatur FBP memenuhi spesifikasi, yaitu $<370{ }^{\circ} \mathrm{C}$, ini berarti sifat penguapan contoh-contoh solar yang diteliti cukup baik sehingga proses pembakaran dalam bahan bakar diesel berlangsung baik.

\section{KESIMPULAN DAN SARAN}

\subsection{Kesimpulan}

Dari pembahasan tersebut, maka kesimpulan dari penelitian ini, yaitu :

1. Hasil pengujian bahan bakar Automotive Diesel Oil dari beberapa SPBU menunjukkan bahwa karakteristik yang diteliti umumnya masih memenuhi spesifikasi baik penggunaannya sebagai bahan bakar mesin diesel maupun persyaratan transaksi dan transportasi.

2. Adanya kemungkinan blending produk Automotive Diesel Oil dari kilang-kilang ilegal yang tidak dapat dipertanggung jawabkan ternyata tidak terindikasi.

\section{DAFTAR PUSTAKA}

Donal, Q. Kern. 1950. Process Heat Transfer. New York Toronto Canada: Mc. Graw Hill Book Company
Hanif, Analisis Sifat Fisik dan Kimia Biodiesel dari Minyak Jelantah Sebagai Bahan Bakar Alternatif Motor Diesel, Jurnal Teknik Mesin, Vol. 6, No.2, Des.2009, ISSN 18298958

Haryanto, B.. 2002. Bahan Bakar Alternatif Biodiesel (Bagian I. Pengenalan). Jurnal Teknik Kimia USU.

Hikmah, M.N., Zuliyana, Pembuatan Metil Ester (Biodiesel) dari Minyak Dedak dan Methanol dengan Proses Esterifikasi dan Transesterifikasi. Jurnal Teknik Kimia, UNDIP. Juni 2010.

Spesifikasi BBM Jenis Solar 48 Standar Pertamina. Maret 2016. Pertamina 
P-ISSN: 2089-5925 E-ISSN: 2621-9328

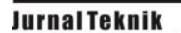

Jurnal Teknik Patra Akademika

PA

Arademika

Volume 10 No. 01 Juli 2019 